\title{
Catheter removal versus retention in the management of catheter-associated enterococcal bloodstream infections
}

\author{
Jonas Marschall MD¹, Marilyn L Piccirillo BA1, Victoria J Fraser MD¹, Joshua A Doherty BS², \\ David K Warren MD MPH${ }^{1}$; for the CDC Prevention Epicenters Program
}

\begin{abstract}
J Marschall, ML Piccirillo, VJ Fraser, JA Doherty, DK Warren; for the CDC Prevention Epicenters Program. Catheter removal versus retention in the management of catheter-associated enterococcal bloodstream infections. Can J Infect Dis Med Microbiol 2013;24(3):e83-e87.
\end{abstract}

BACKGROUND: Enterococci are an important cause of central venous catheter (CVC)-associated bloodstream infections (CA-BSI). It is unclear whether CVC removal is necessary to successfully manage enterococcal CA-BSI.

METHODS: A 12-month retrospective cohort study of adults with enterococcal CA-BSI was conducted at a tertiary care hospital; clinical, microbiological and outcome data were collected.

RESULTS: A total of 111 patients had an enterococcal CA-BSI. The median age was 58.2 years (range 21 to 94 years). There were 45 (40.5\%) infections caused by Entercoccus faecalis (among which 10 [22\%] were vancomycin resistant), 61 (55\%) by Enterococcus faecium (57 [93\%] vancomycin resistant) and five $(4.5 \%)$ by other Enterococcus species. Patients were treated with linezolid $(n=51$ [46\%]), vancomycin $(n=37[33 \%])$, daptomycin $(n=11[10 \%])$, ampicillin $(n=2[2 \%])$ or quinupristin/dalfopristin $(n=2[2 \%])$; seven $(n=6 \%)$ patients did not receive adequate enterococcal treatment. Additionally, 24 (22\%) patients received adjunctive gentamicin treatment. The CVC was retained in $29(26.1 \%)$ patients. Patients with removed CVCs showed lower rates of in-hospital mortality (15 [18.3\%] versus 11 [37.9]; $\mathrm{P}=0.03$ ), but similar rates of recurrent bacteremia (nine [11.0\%] versus two $(7.0 \%) ; \mathrm{P}=0.7)$ and a similar post-BSI length of hospital stay (median days [range]) (11.1 [1.7 to 63.1 days] versus 9.3 [1.9 to 31.8 days]; $\mathrm{P}=0.3)$. Catheter retention was an independent predictor of mortality (OR 3.34 [95\% CI 1.21 to 9.26$]$ ).

CONCLUSIONS: To the authors' knowledge, the present article describes the largest enterococcal CA-BSI series to date. Mortality was increased among patients who had their catheter retained. Additional prospective studies are necessary to determine the optimal management of enterococcal CA-BSI.

Key Words: Bacteremia; Central venous catheter; Enterococcus; Management

E nterococci are the third most frequent cause of nosocomial bloodstream infections, constituting $9.4 \%$ to $11.1 \%$ of the pathogens recovered in two large United States studies $(1,2)$. They also rank as the third most frequent bacterial cause of catheter-associated bloodstream infections (CA-BSI) (3). Clinical isolates most commonly belong to one of two subspecies, Enterococcus faecalis and Enterococcus faecium (4). Biofilm formation has been observed more frequently both in device-related bloodstream infections due to E faecalis (5) and E faecium (6) when compared with other sources of infection or commensal enterococci, respectively. It has, therefore, been suggested as a marker of virulence. Biofilm formation also decreases local antimicrobial susceptibility $(7,8)$. Because eradication of an established biofilm from an indwelling device is difficult to

\section{Le retrait ou le maintien du cathéter dans la prise en charge des bactériémies liées à un cathéter}

HISTORIQUE : Les entérocoques constituent une cause importante de bactériémies liées à un cathéter veineux central (CVC). On ne sait pas s'il est nécessaire de retirer le CVC pour réussir la prise en charge de ce type de bactériémie.

MÉTHODOLOGIE : Les auteurs ont mené une étude rétrospective de cohorte de 12 mois auprès d'adultes ayant une bactériémie liée à un CVC dans un hôpital de soins tertiaires. Ils ont colligé des données cliniques, des données microbiologiques et des données d'issue.

RÉSULTATS : Au total, 111 patients étaient atteints d'une bactériémie à entérocoque liée à un CVC. Ils avaient un âge médian de 58,2 ans (plage de 21 à 94 ans). Les chercheurs ont constaté 45 infections (40,5\%) causées par l'Enterococcus faecalis (dont 10 [22\%] résistantes à la vancomycine), 61 infections (55\%) causées par l'Enterococcus faecium (dont 57 [93\%] résistantes à la vancomycine) et cinq (4,5\%) causées par d'autres espèces d'Enterococcus. Les patients ont été traités au linézolide $(\mathrm{n}=51$ [46 \%]), à la vancomycine $(\mathrm{n}=37$ [33 \%]), à la daptomycine $(n=11[10 \%])$, à l'ampicilline $(n=2[2 \%])$ ou à la quinupristine-dalfopristine $(n=2[2 \%])$. Sept patients $(n=6 \%)$ n'ont pas reçu de traitement convenable contre les entérocoques. De plus, 24 patients $(22 \%)$ ont reçu un traitement d'appoint à la gentamicine. Vingt-neuf patients $(26,1 \%)$ ont conservé leur CVC. Les patients à qui on l'avait retiré présentaient des taux de mortalité hospitalière plus faibles (15 [18,3\%] par rapport à $11[37,9] ; \mathrm{P}=0,03)$, mais des taux similaires de bactériémie récurrente (neuf [11,0\%] par rapport à deux $(7,0 \%) ; \mathrm{P}=0,7)$ et une durée d'hospitalisation similaire après la bactériémie (jours médians [plage]) (11,1 [1,7 à 63,1 jours] par rapport à 9,3 [1,9 à 31,8 jours]; $\mathrm{P}=0,3)$. Le maintien du cathéter était un prédicteur indépendant de mortalité (RRR 3,34 [95 \% IC 1,21 à 9,26]). CONCLUSIONS : En autant que le sache les auteurs, le présent article décrit la plus grosse série de bactériémies liées à un CVC. La mortalité était plus élevée chez les patients qui conservaient leur cathéter. D'autres études prospectives s'imposent pour déterminer la prise en charge optimale de la bactériémie à entérocoque liée à un CVC.

\footnotetext{
${ }^{1}$ Division of Infectious Diseases, Washington University School of Medicine; ${ }^{2}$ Medical Informatics, BJC Healthcare, St Louis, Missouri, USA Correspondence: Dr Jonas Marschall, Department of Infectious Diseases, Bern University Hospital and University of Bern, Friedbühlstrasse 51,

Bern 3010, Switzerland. Telephone 41-31-632-9992, e-mail jonas.marschall@insel.ch
} 


\section{METHODS}

\section{Setting}

Barnes-Jewish Hospital (BJH), a 1250-bed teaching hospital, is the largest hospital in Missouri (USA), and has a referral base that includes the St Louis Metropolitan area, eastern Missouri and western Illinois. It houses all medical specialties, including a stem cell transplantation unit. BJH is affiliated with the Washington University School of Medicine (St Louis, Missiouri, USA).

\section{Study design}

A retrospective cohort study of patients with enterococcal CA-BSIs during their hospital stay was performed. CA-BSI was defined as enterococcal bacteremia in a patient with a central venous catheter (CVC) in place for at least $48 \mathrm{~h}$ and no alternative source of infection. The hospital's medical informatics database was queried for blood cultures positive for any Enterococcus species; this dataset was merged with a manually collected dataset of CVC usage in the hospital, which is part of the hospital infection control database.

\section{Inclusion and exclusion criteria}

Adult patients admitted to BJH between January 1, 2006 and December 31, 2006, who presented with, or developed, an enterococcal bloodstream infection and had a CVC present at the time of detection of this infection were included. All types and locations of CVCs were included. Blood cultures were obtained during routine care either peripherally and/or from the CVC. Patients who presented to the hospital with a CVC already in place were included. Patient history and physical examination as well as admitting diagnosis and microbiology results were reviewed to determine whether the catheter was the primary focus of the bacteremia. Patients with a primary focus of bacteremia other than the catheter, patients with a CVC in place for $<48 \mathrm{~h}$, and patients who died on the day of the positive blood culture were excluded. Polymicrobial infections were included except concurrent Staphylococcus aureus bacteremia or candidemia within \pm 3 days of the enterococcal bacteremia $(n=20)$ because both entities are established indications for catheter removal.

\section{Data collection}

Demographic characteristics, medical history, clinical presentation, diagnostic and therapeutic procedures, antibiotic treatment and key markers of outcome (recurrence of bloodstream infection, length of hospital stay after the bloodstream infection, crude mortality) were abstracted from the medical records. Admission Charlson comorbidity and McCabe severity of illness scores were determined. Duration of catheter retention time after the bacteremia was recorded. Information on antibiotic lock therapy was collected; however, this treatment modality was not used in patients from this cohort.

Postdischarge mortality at both 30 days and three months after bacteremia was obtained from the Social Security Death Index (www. ssdi-search.com).

\section{Definitions}

Renal insufficiency was defined by a serum creatinine level $>132.6 \mu \mathrm{mol} / \mathrm{L}$. Sepsis and sepsis-induced hypotension were defined using established criteria (13). Appropriate therapy was defined as pathogen-directed treatment with antibiotics matching susceptibilities. A catheter was considered to be retained if it was present for the duration of the hospitalization after the first positive blood culture. Recurrence of bacteremia (used here synonymously with intermittent bacteremia) was defined as a second positive blood culture after $\geq 1$ negative blood culture and an interval of $\geq 1$ day during their hospitalization. Community-onset enterococcal bloodstream infection was defined as having the first positive blood culture drawn within $48 \mathrm{~h}$ of hospital admission.

\section{Data analysis and statistical methods}

Data entry was performed using Access and Excel (Microsoft Corporation, USA). Data analysis was performed using SPSS 17 (IBM
Corporation, USA). Univariate comparisons among categorical variables and outcome measures were performed using the $\chi^{2}$ test or Fisher's exact test. A two-sided $\mathrm{P}<0.05$ was considered to be statistically significant. Also calculated was the absolute difference in proportion $\left(\Delta_{\mathrm{p}}\right)$ of rates of outcome measures including the $95 \% \mathrm{CI}$ of this difference to describe the precision of this point estimate. Analysis of the difference in proportions and $95 \% \mathrm{CI}$ enabled the interpretation of statistical significance (if the 95\% CI did not cross zero) as well as clinical significance (if the upper limit of the $95 \%$ CI exceeded a predefined difference). An absolute difference in recurrence of bacteremia and mortality rates of $15 \%$ was considered to represent a clinically significant difference; this estimate was chosen based on previous literature regarding catheter management and clinical experience $(14,15)$. Comparisons among continuous independent variables were performed using the Student's $t$ test or Mann-Whitney U test as appropriate. Variables found to have $\mathrm{P}<0.1$ in univariate testing were considered for entry into a forward, stepwise multivariate logistic regression model.

The study was approved by the Washington University Human Research Protection Office (\#07-0690).

\section{RESULTS}

Demographics, comorbidities and clinical presentation

There were 111 patients with enterococcal CA-BSI who met inclusion criteria. The mean $( \pm \mathrm{SD})$ age was $58.2 \pm 15.3$ years; $56(50.5 \%)$ patients were male; and $77(69.4 \%)$ were white. There were $36(32 \%)$ patients admitted to the oncology/bone marrow transplant service. The most frequent comorbidities were malignancies $(n=62[55.9 \%])$, diabetes $(n=35[31.5 \%])$ and renal insufficiency $(n=31$ [27.9\%]). Twenty-five (22.5\%) patients had metastatic solid tumours, 28 (25.2\%) had leukemia, six (5.4\%) had lymphomas and three (2.7\%) had nonmetastatic solid tumours. There were $20(18 \%)$ patients who were neutropenic at the time of bloodstream infection. Of all bloodstream infections, $90(81 \%)$ were hospital-acquired. None of the patients were diagnosed with infective endocarditis during the admission.

\section{Microbiology}

Of the enterococcal bloodstream infections, 45 (40.5\%) were caused by $E$ faecalis and $61(55.0 \%)$ by $E$ faecium. Of the bacteremias caused by $E$ faecalis, 10 (22.2\%) were due to vancomycin-resistant isolates while 57 (93.4\%) of the bacteremias caused by E faecium were vancomycin resistant. An additional five (4.5\%) infections were caused by other Enterococcus species. A total of 37 patients (33.3\%) had polymicrobial infections in which the most common polymicrobial organism was coagulase-negative Staphylococcus ( $n=26$ [23.4\%]). There were $24(34.9 \%)$ polymicrobial E faecalis bacteremias and $10(27.0 \%)$ polymicrobial E faecium bacteremias. Additionally, there was no difference in polymicrobial bacteremias among patients who had their catheter removed versus retained (28 [34.1\%] versus nine [31.0\%]; $\mathrm{P}=0.8$ ).

Vancomycin-susceptible E faecalis caused 30 (36.6\%) of 82 infections in which catheters were removed during the hospitalization and five $(17.2 \%)$ of 29 infections in which they were retained $(P=0.09)$. Vancomycin-resistant E faecium (VRE) caused 42 (51.2\%) of infections in which catheters were removed and 15 (51.7\%) in which they were retained $(P=0.9)$. Overall, there was no difference in the number of vancomycin-resistant isolates regardless of whether a catheter was removed (49 of 82 [59.8\%] versus 18 of 29 [62.1\%]; P=1.0). Of the 26 patients who died during hospitalization, $19(73.1 \%)$ had vancomycin-resistant enterococcal bacteremia.

\section{Antibiotic treatment}

Patients were treated most frequently with linezolid ( $\mathrm{n}=51$ [45.9\%]) or vancomycin $(n=37$ [33.3\%]). Smaller subsets were given daptomycin $(\mathrm{n}=11[9.9 \%])$, ampicillin $(\mathrm{n}=2[1.8 \%])$ or quinupristin/dalfopristin $(n=2[1.8 \%])$. Of the seven $(6.3 \%)$ patients who did not receive adequate enterococcal treatment, five had their catheter removed 
TABLE 1

Comparison of characteristics of patients with enterococcal catheter-associated bloodstream infections managed with catheter removal versus catheter retention during hospitalization

\begin{tabular}{|c|c|c|c|}
\hline \multirow[b]{2}{*}{ Variable } & \multicolumn{2}{|c|}{ Catheter } & \multirow[b]{2}{*}{$\mathbf{P}$} \\
\hline & $\begin{array}{c}\text { Removed } \\
(n=82)\end{array}$ & $\begin{array}{l}\text { Retained } \\
(n=29)\end{array}$ & \\
\hline \multicolumn{4}{|c|}{ Demographics and clinical characteristics } \\
\hline Age, years, mean $\pm S D$ & $58.7 \pm 15.6$ & $56.6 \pm 14.7$ & 0.52 \\
\hline $\begin{array}{l}\text { Charlson comorbidity index score, } \\
\text { mean } \pm \text { SD }\end{array}$ & $3.1 \pm 3.0$ & $3.4 \pm 3.4$ & 0.58 \\
\hline McCabe severity score, mean \pm SD & $2.0 \pm 0.82$ & $1.8 \pm 0.76$ & 0.29 \\
\hline \multicolumn{4}{|l|}{ Service on admission } \\
\hline General internal medicine & $29(35.4)$ & $10(34.5)$ & 0.93 \\
\hline Oncology/bone marrow transplant & $25(30.5)$ & $11(37.9)$ & 0.46 \\
\hline \multicolumn{4}{|l|}{ Comorbidities } \\
\hline Malignant tumour & $46(56.1)$ & $16(55.2)$ & 0.93 \\
\hline Diabetes mellitus & $27(32.9)$ & $8(27.6)$ & 0.59 \\
\hline Renal insufficiency $(\mathrm{Cr}>132.6 \mu \mathrm{mol} / \mathrm{L})$ & $22(26.8)$ & $9(31.0)$ & 0.66 \\
\hline Metastatic solid tumour & $18(22.0)$ & $7(24.1)$ & 0.81 \\
\hline Sepsis & $71(86.6)$ & $25(86.2)$ & 1.00 \\
\hline Sepsis-induced hypotension & $28(34.1)$ & $12(41.4)$ & 0.49 \\
\hline Multiorgan dysfunction & $7(8.5)$ & $1(3.4)$ & 0.68 \\
\hline $\begin{array}{l}\text { Neutropenic at time of positive } \\
\text { blood culture }\end{array}$ & $17(20.7)$ & $3(10.3)$ & 0.27 \\
\hline \multicolumn{4}{|l|}{ Microbiology } \\
\hline Enterococcus faecalis & $37(45.1)$ & $8(27.6)$ & 0.10 \\
\hline E faecalis, vancomycin resistant & $7(8.5)$ & $3(10.3)$ & 0.72 \\
\hline Enterococcus faecium & $44(53.7)$ & $17(58.6)$ & 0.64 \\
\hline E faecium, vancomycin resistant & $42(51.2)$ & $15(51.7)$ & 0.87 \\
\hline Polymicrobial bacteremia & $28(34.1)$ & $9(31.0)$ & 0.76 \\
\hline $\begin{array}{l}\text { VRE detection in stool } \\
\text { (tested in } n=100 \text { ) }\end{array}$ & $41 / 82(50.0)$ & $17 / 29(58.6)$ & 0.42 \\
\hline \multicolumn{4}{|l|}{ Treatment } \\
\hline $\begin{array}{l}\text { Duration of antibiotic treatment, } \\
\text { days, mean } \pm \text { SD }\end{array}$ & $10.8 \pm 8.4$ & $7.5 \pm 6.0$ & 0.06 \\
\hline Adjunctive gentamicin treatment & $19(23.2)$ & $5(17.2)$ & 0.50 \\
\hline
\end{tabular}

Data presented as $n$ (\%) unless otherwise indicated. $\mathrm{Cr}$ Creatinine; VRE Vancomycin-resistant Enterococcus faecium

during the admission. In addition to one of the antibiotics above, $24(21.6 \%)$ patients received adjunctive treatment with gentamicin. Due to discharge or in-hospital mortality, the mean duration of inhospital antibiotic treatment was limited to $10.0 \pm 8.0$ days. Data regarding postdischarge antibiotics were not collected.

\section{Catheter management}

The CVC was retained during the hospitalization in 29 (26.1\%) patients. In univariate analysis, patients with removed CVCs were similar to patients whose CVC was retained (Table 1).

In terms of outcomes, however (Table 2), patients with removed CVCs showed both lower in-hospital mortality (15 [18.3\%] versus 11 [37.9\%]; $\Delta_{p}=16 \%$ [95\% CI $2 \%$ to $39 \%$ ]; $\mathrm{P}=0.03$ ), and lower 30 -day mortality $\left(21\right.$ [25.6\%] versus 13 [44.8\%]; $\Delta_{\mathrm{p}}=16 \%$ [95\% CI $-0.2 \%$ to $39 \%$ ]; $\mathrm{P}=0.05$ ). In contrast, rates were similar in patients who had their CVC removed or retained for recurrent bacteremia (nine [11.0\%] versus two [7.0\%]; $\Delta_{\mathrm{p}}=4 \%$ [95\% CI $-14 \%$ to $12 \%$ ]; $\mathrm{P}=0.7$ ), median (range in days) post-bacteremia length of hospital stay (11.1 [1.7 to 63.1 days] versus 9.3 [1.9 to 31.8 days]; $\Delta_{\mathrm{p}}=1.8$ days [95\% CI -2.1 to 5.6 days]; $\mathrm{P}=0.31$ ) and three-month mortality (32 [39.0\%] versus $15[51.7 \%] ; \Delta_{\mathrm{p}}=10 \%$ [95\% CI $-8 \%$ to $\left.32 \%\right] ; \mathrm{P}=0.2$ ).
TABLE 2

Comparison of outcome measures of patients with enterococcal catheter-associated bloodstream infections managed with catheter removal versus catheter retention during hospitalization

\begin{tabular}{|c|c|c|c|c|c|}
\hline \multirow[b]{2}{*}{$\begin{array}{l}\text { Outcome } \\
\text { measure }\end{array}$} & \multicolumn{2}{|c|}{ Catheter, n (\%) } & \multirow[b]{2}{*}{$\mathbf{P}$} & \multirow[b]{2}{*}{$\Delta_{p}{ }^{*}, \%$} & \multirow[b]{2}{*}{$95 \% \mathrm{Cl}^{\dagger}$} \\
\hline & $\begin{array}{c}\text { Removed } \\
(n=82)\end{array}$ & $\begin{array}{c}\text { Retained } \\
(n=29)\end{array}$ & & & \\
\hline $\begin{array}{l}\text { Recurrence of } \\
\text { enterococcal } \\
\text { bloodstream } \\
\text { infection }\end{array}$ & $9(11.0)$ & $2(7.0)$ & 0.72 & 4 & $(-14 \%$ to $12 \%)$ \\
\hline $\begin{array}{l}\text { In-hospital crude } \\
\text { mortality }\end{array}$ & $15(18.3)$ & $11(37.9)$ & 0.03 & 16 & ( $2 \%$ to $39 \%)$ \\
\hline $\begin{array}{l}\text { Mortality within } \\
30 \text { days of the } \\
\text { first positive } \\
\text { culture }\end{array}$ & $21(25.6)$ & $13(44.8)$ & 0.05 & 16 & $(-0.2 \%$ to $39 \%)$ \\
\hline $\begin{array}{l}\text { Mortality within } \\
\text { three months of } \\
\text { the first positive } \\
\text { culture }\end{array}$ & $32(39.0)$ & $15(51.7)$ & 0.23 & 10 & $(-8 \%$ to $32 \%)$ \\
\hline \multicolumn{6}{|c|}{$\begin{array}{l}{ }^{*} \Delta_{p} \text { represents the difference in proportions between the two catheter man- } \\
\text { agement groups; }{ }^{\dagger} \text { The } 95 \% \mathrm{Cl} \text { represents the precision of this estimate by } \\
\text { describing statistical significance ( } 95 \% \mathrm{Cl} \text { does not cross } 0 \text { ) as well as clinical } \\
\text { significance (the upper bound of the } 95 \% \mathrm{Cl} \text { exceeds the predetermined 'clini- } \\
\text { cally significant' change in outcome rates of } 15 \%)\end{array}$} \\
\hline
\end{tabular}

Risk factors for mortality

A number of risk factors for mortality were identified in univariate analyses (Table 3). Patients who had VRE detected in stool were more likely to die in the hospital (19 of 58 [32.8\%] versus five of 42 [11.9\%] with negative VRE screening; $\mathrm{P}=0.02$ ), as were those with $E$ faecium bloodstream infection (18 of 61 [29.5\%] versus eight of 50 [16.0\%] with other enterococcal species; $\mathrm{P}=0.09)$, and patients managed with CVC retention (11 of 29 [37.9\%] versus 15 of 82 [18.3\%] in whom the $\mathrm{CVC}$ was removed; $\mathrm{P}=0.03$ ).

These three factors - VRE colonization, E faecium bloodstream infection and catheter retention - were entered in a multivariate model using logistic regression. The analysis showed that VRE colonization (OR 3.19 [95\% CI 1.02 to 10.01]) and catheter retention (OR 3.34 [95\% CI 1.21 to 9.26]) were independently associated with in-hospital mortality.

\section{DISCUSSION}

Removal of an intravascular catheter is, with few exceptions, considered to be an essential part of managing CA-BSI. However, robust data to support this approach are only available for a limited number of pathogens responsible for these infections. Despite the lack of sufficient data to provide an evidence-based recommendation with regard to CA-BSI caused by Enterococcus species, national guidelines recommend removing the involved catheters (9). To our knowledge, the present study represents the largest investigation into catheter management and outcomes of enterococcal bloodstream infections.

The main finding of the present study was increased mortality in patients whose catheters were retained during the hospitalization. Our findings suggest that catheter removal should be considered to improve patient survival. Also, the difference in the two outcome proportions exceeded the predetermined clinically meaningful difference of $15 \%$, which gives us a quantitative estimate of the impact of catheter removal. The patient groups were very similar with respect to demographic characteristics and comorbidities, including adjunctive antibiotic treatment with the aminoglycoside gentamicin. These findings are congruent with the single study encountered in the scientific literature that scrutinized outcomes of enterococcal CA-BSI and specifically investigated catheter management, albeit in a smaller number of 


\begin{tabular}{|c|c|c|c|c|}
\hline Variable & $\begin{array}{c}\text { Died } \\
(n=26)\end{array}$ & $\begin{array}{c}\text { Survived } \\
(\mathrm{n}=85)\end{array}$ & $\mathbf{P}$ & $\begin{array}{c}\text { OR } \\
(95 \% \mathrm{Cl}) \\
\end{array}$ \\
\hline Age, years, mean \pm SD & $59.0 \pm 17.3$ & $57.9 \pm 14.8$ & 0.8 & \\
\hline Male sex & $13(50.0)$ & $43(50.6)$ & 1.0 & \\
\hline Body mass index, $\mathrm{kg} / \mathrm{m}^{2}$ & $29.9(9.0)$ & $28.4(7.2)$ & 0.4 & \\
\hline \multicolumn{5}{|l|}{ Comorbidities } \\
\hline $\begin{array}{l}\text { Charlson comorbidity index } \\
\text { score, mean } \pm \text { SD }\end{array}$ & $4.3 \pm 4.5$ & $2.8 \pm 2.4$ & 0.1 & \\
\hline Malignant tumour & $15(57.7)$ & $44(51.8)$ & 0.6 & \\
\hline Diabetes mellitus & $11(42.3)$ & $24(28.2)$ & 0.2 & \\
\hline $\begin{array}{l}\text { Renal insufficiency } \\
\qquad(\mathrm{Cr}>132.6 \mu \mathrm{mol} / \mathrm{L})\end{array}$ & $9(34.6)$ & $22(25.9)$ & 0.4 & \\
\hline Metastatic solid tumour & $5(19.2)$ & $20(23.5)$ & 0.6 & \\
\hline Sepsis & $24(92.3)$ & $72(84.7)$ & 0.5 & \\
\hline Sepsis-induced hypotension & $14(53.8)$ & $26(30.6)$ & 0.03 & \\
\hline Multiorgan dysfunction & $6(23.1)$ & $2(2.4)$ & 0.002 & \\
\hline Development of neutropenia & $7(26.9)$ & $19(22.4)$ & 0.6 & \\
\hline $\begin{array}{l}\text { Neutropenic at time of positive } \\
\text { blood culture }\end{array}$ & $3(11.5)$ & $17(20.0)$ & 0.4 & \\
\hline Hospital-acquired CA-BSI & $23(88.5)$ & $67(78.8)$ & 0.4 & \\
\hline $\begin{array}{l}\text { Recurrence of enterococcal } \\
\text { bloodstream infection }\end{array}$ & $5(19.2)$ & $6(7.1)$ & 0.1 & \\
\hline \multicolumn{5}{|l|}{ Microbiology } \\
\hline Enterococcus faecalis & 8 & 37 & 0.2 & \\
\hline E faecalis, vancomycin-resistant & 2 & 8 & 1.0 & \\
\hline Enterococcus faecium & 18 & 43 & 0.09 & $\begin{array}{c}1.37 \\
(0.48-3.90)\end{array}$ \\
\hline E faecium, vancomycin-resistant & 17 & 40 & 0.1 & \\
\hline Polymicrobial bacteremia & $7(26.9)$ & $30(35.7)$ & 0.4 & \\
\hline $\begin{array}{l}\text { VRE detection in stool, } \mathrm{n} / \mathrm{n}(\%) \\
\text { (tested in } \mathrm{n}=100 \text { ) }\end{array}$ & $\begin{array}{l}19 / 24 \\
(79.2)\end{array}$ & $\begin{array}{l}39 / 76 \\
(51.3)\end{array}$ & 0.02 & $\begin{array}{c}3.19 \\
(1.12-10.01)\end{array}$ \\
\hline \multicolumn{5}{|l|}{ Treatment } \\
\hline Catheter retained & $11(42.3)$ & $18(21.2)$ & 0.03 & $\begin{array}{c}3.34 \\
(1.21-9.26)\end{array}$ \\
\hline $\begin{array}{l}\text { Duration of antibiotic treatment, } \\
\text { days, mean } \pm \text { SD }\end{array}$ & $9.2 \pm 7.4$ & $10.2 \pm 8.2$ & 0.6 & \\
\hline Adjunctive gentamicin treatment & $8(30.8)$ & 16 (18.8) & 0.2 & \\
\hline
\end{tabular}

Data presented $n$ (\%) unless otherwise indicated. $\mathrm{Cr}$ Creatinine; VRE Vancomycin-resistant E faecium

patients (11). There, the authors retrospectively examined 61 enterococcal CA-BSI, with $82 \%$ of the episodes due to $E$ faecalis and polymicrobial infections found in $18 \%$ of the study population. Of note, they did not exclude patients with concurrent Staphylococcus aureus or yeast bloodstream infections, although these infections likely guided catheter management significantly more than the detection of enterococci. Sandoe et al (11) evaluated whether successful treatment of a bloodstream infection was possible without removal of the catheter, which was achieved in five of 13 cases (38\%). If the catheter was removed, the chance for cure was higher (40 of 48 [83\%]). They found a combination of a cell wall-active agent with an aminoglycoside to be significantly more effective than monotherapy when the catheter was retained. The authors concluded that, although the removal of the catheter was performed in the majority of cases, it did not appear to be a necessary part of the management as long as antimicrobial treatment was optimized. In our study, even though we did not set cure as an end point, $67(81.7 \%)$ of 82 patients with catheters removed survived the hospital admission and $61(74.4 \%)$ survived at 30 days postbacteremia. These rates were much lower for patients with retained catheters. In summary, these data suggest that although enterococcal CA-BSI are not an absolute indication for catheter removal, removal should be favoured over catheter retention.

Reasons for catheter retention may have been that the treating physicians of patients who were severely ill at the time of enterococcal bloodstream infection were reluctant to remove the catheter because it was essential for nonantibiotic medications; that the patients had limited options for alternative intravenous access; or that their comorbidities increased the risk of catheter removal and replacement. Catheter management may have been driven by reasons other than the infection alone, and removing the catheter could have been a lower priority or higher risk in the patients' overall medical management. Because we collected crude mortality data, it is also conceivable that patients died from causes not related to the CA-BSI. Of note, we did not observe a difference in recurrence of infection depending on catheter management; it is possible that the size of the cohort prevented us from noting a statistically significant difference.

Our patients are notable for a high percentage of comorbid conditions, including metastatic solid tumours (23\%) and leukemia (25\%); accordingly, the crude in-hospital mortality rate was high in our study population. An independent factor associated with death was the detection of VRE in the stool, which may be a marker for frequent health care exposure. Despite this finding, CA-BSIs with vancomycinresistant $E$ faecium did not result in increased mortality compared with non-VRE infections. This is different from an earlier prospective study and a more recent meta-analysis, in which vancomycin resistance was found to be associated with increased mortality $(16,17)$. Most likely, we could not replicate this association due to the small sample size. However, the association of VRE colonization with mortality has been demonstrated previously in a cohort of bone marrow transplant patients (18).

Limitations of the present study include its retrospective design, the fact that the diagnosis of recurrent infection depended on the treating physician ordering blood cultures and that postdischarge outcomes, including completion of planned antibiotic therapy, follow-up blood cultures, and catheter removal postdischarge, were not studied. In addition, catheter management is potentially influenced by other reasons for retention (difficulty of finding alternative access, bleeding diathesis) and we did not report outcomes for different catheter types. Finally, changes in the usage of daptomycin and linezolid have occurred since the time of the study. Although this was the largest study of enterococcal CA-BSI to date, it is still a relatively small sample to detect rare outcomes.

\section{CONCLUSIONS}

Based on our study findings, catheter removal is preferable to retention in patients with enterococcal CA-BSI. A large prospective or multicentre study should be performed to identify patients at highest risk for mortality and to add strength to our results.

DECLARATIONS: None of the following authors has a conflict of interest to declare: J Marschall, ML Piccirillo, J Doherty. VJ Fraser is a consultant for Merck and Member of the Speakers' Bureau for Pfizer, Merck and Cubist Pharmaceuticals. DK Warren is a consultant for $3 \mathrm{M}$ Healthcare and Cardinal Health, and receives research funding from Sage Products Inc, Cubist Pharmaceuticals and 3M Healthcare.

AUTHORS' CONTRIBUTIONS: JM and DKW devised the study; JAD generated the query based on the Medical Informatics and Infection Control databases; VJF assisted in study design; JM and MLP collected and analyzed the data, and wrote the manuscript; all authors critically reviewed the final draft of the manuscript.

ACKNOWLEDGEMENTS: This study itself was performed without external financial support. JM was supported by a CTSA KL2 Career Development Award (5KL2RR024994-03) and a research grant from the Swiss National Science Foundation (PBBSB-113014); he currently receives support from the Building Interdisciplinary Research Careers in Women's 
Health (BIRCWH) award through the NIH (5K12HD001459-13) and the CDC Prevention Epicenters Program grant (U54 CK000162). In addition, JM is funded by the Barnes-Jewish Hospital Patient Safety \& Quality Fellowship Program and by a research grant from the Barnes-Jewish Hospital Foundation \& Washington University's Institute for Clinical and Translational Sciences. VJF (IK24 AI 06779401) is funded through an NIH grant. DKW and VJF received a CDC Prevention Epicenters Program grant (U54 CK000162). The authors thank Cherie Hill and Dorothy Sinclair for their invaluable data management.

\section{REFERENCES}

1. Edmond MB, Wallace SE, McClish DK, Pfaller MA, Jones RN, Wenzel RP. Nosocomial bloodstream infections in United States hospitals: A three-year analysis. Clin Infect Dis 1999;29:239-44.

2. Wisplinghoff H, Bischoff T, Tallent SM, Seifert H, Wenzel RP, Edmond MB. Nosocomial bloodstream infections in US hospitals: Analysis of 24,179 cases from a prospective nationwide surveillance study. Clin Infect Dis 2004;39:309-17.

3. Raad, II, Hanna HA. Intravascular catheter-related infections: New horizons and recent advances. Arch Intern Med 2002;162:871-8.

4. Murray BE. The life and times of the Enterococcus. Clin Microbiol Rev 1990;3:46-65.

5. Sandoe JA, Witherden IR, Cove JH, Heritage J, Wilcox MH. Correlation between enterococcal biofilm formation in vitro and medical-device-related infection potential in vivo. J Med Microbiol 2003;52:547-50.

6. Raad, II, Hanna HA, Boktour M, et al. Vancomycin-resistant Enterococcus faecium: Catheter colonization, esp gene, and decreased susceptibility to antibiotics in biofilm.

Antimicrob Agents Chemother 2005;49:5046-50.

7. Sandoe JA, Wysome J, West AP, Heritage J, Wilcox MH. Measurement of ampicillin, vancomycin, linezolid and gentamicin activity against enterococcal biofilms. J Antimicrob Chemother 2006;57:767-70.

8. Wiederhold NP, Coyle EA, Raad, II, Prince RA, Lewis RE. Antibacterial activity of linezolid and vancomycin in an in vitro pharmacodynamic model of Gram-positive catheter-related bacteraemia. J Antimicrob Chemother 2005;55:792-5.

9. Mermel LA, Allon M, Bouza E, et al. Clinical practice guidelines for the diagnosis and management of intravascular catheter-related infection: 2009 Update by the Infectious Diseases Society of America. Clin Infect Dis 2009;49:1-45.

10. Raad, II, Hanna HA, Boktour M, Jabbour N, Hachem RY, Darouiche RO. Catheter-related vancomycin-resistant Enterococcus faecium bacteremia: Clinical and molecular epidemiology. Infect Control Hosp Epidemiol 2005;26:658-61.

11. Sandoe JA, Witherden IR, Au-Yeung HK, Kite P, Kerr KG, Wilcox MH. Enterococcal intravascular catheter-related bloodstream infection: Management and outcome of 61 consecutive cases. J Antimicrob Chemother 2002;50:577-82.

12. Reigadas E, Rodriguez-Creixems M, Guembe M, Sanchez-Carrillo C, Martin-Rabadan P, Bouza E. Catheter-related bloodstream infection caused by Enterococcus spp. Clin Microbiol Infect 2013;19:457-61.

13. Bone RC, Balk RA, Cerra FB, et al. Definitions for sepsis and organ failure and guidelines for the use of innovative therapies in sepsis. The ACCP/SCCM Consensus Conference Committee. American College of Chest Physicians/Society of Critical Care Medicine. Chest 1992;101:1644-55.

14. Raad I, Davis S, Khan A, Tarrand J, Elting L, Bodey GP. Impact of central venous catheter removal on the recurrence of catheter-related coagulase-negative staphylococcal bacteremia. Infect Control Hosp Epidemiol 1992;13:215-21.

15. Nguyen MH, Peacock JE Jr, Tanner DC, et al. Therapeutic approaches in patients with candidemia. Evaluation in a multicenter, prospective, observational study. Arch Intern Med 1995;155:2429-35.

16. Vergis EN, Hayden MK, Chow JW, et al. Determinants of vancomycin resistance and mortality rates in enterococcal bacteremia. a prospective multicenter study. Ann Intern Med 2001;135:484-92.

17. DiazGranados CA, Zimmer SM, Klein M, Jernigan JA. Comparison of mortality associated with vancomycin-resistant and vancomycin-susceptible enterococcal bloodstream infections: A meta-analysis. Clin Infect Dis 2005;41:327-33.

18. Zirakzadeh A, Gastineau DA, Mandrekar JN, Burke JP, Johnston PB, Patel R. Vancomycin-resistant enterococcal colonization appears associated with increased mortality among allogeneic hematopoietic stem cell transplant recipients. Bone Marrow Transplant 2008;41:385-92. 


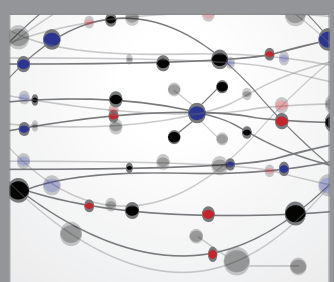

The Scientific World Journal
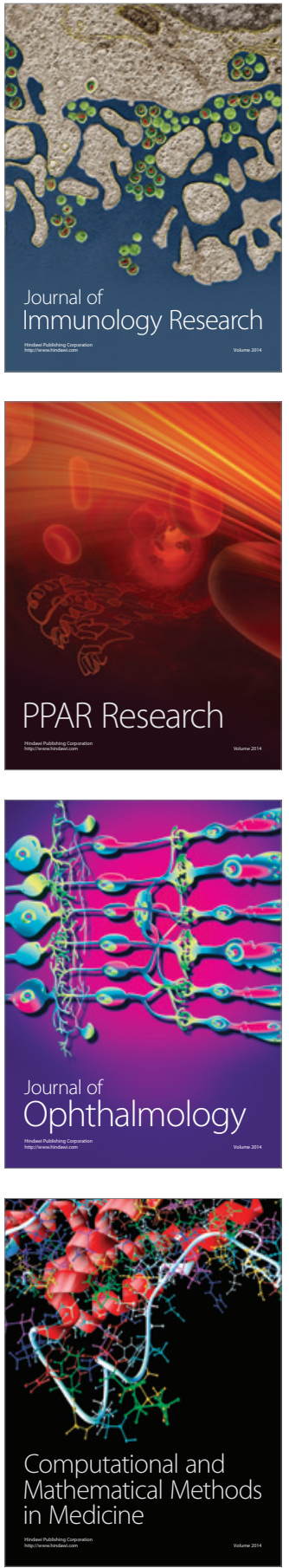

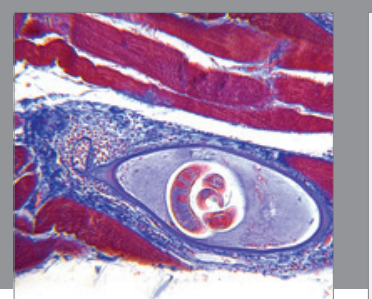

Gastroenterology Research and Practice

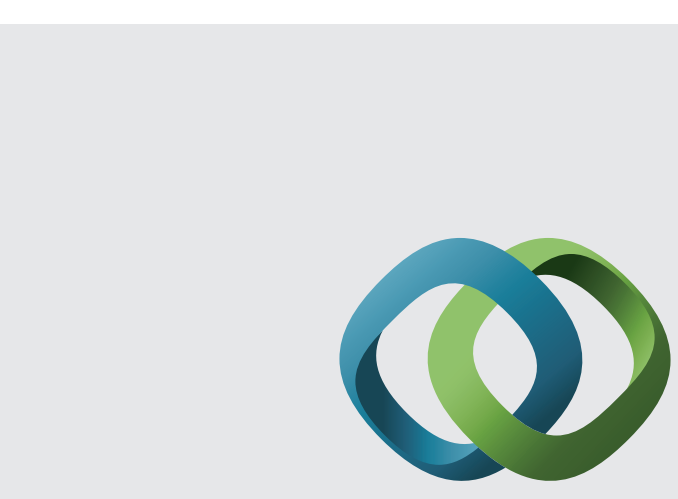

\section{Hindawi}

Submit your manuscripts at

http://www.hindawi.com
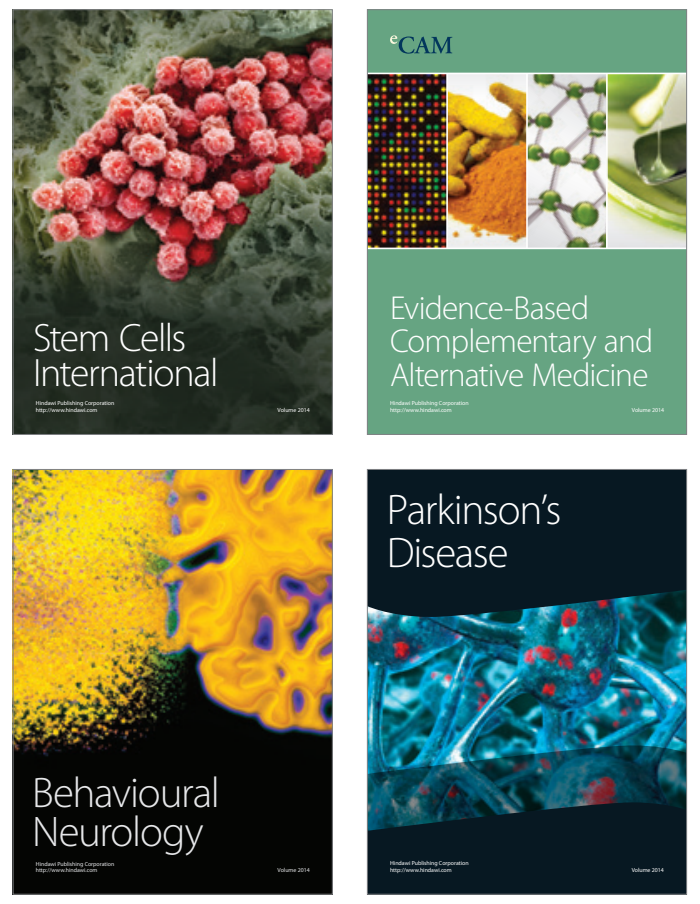
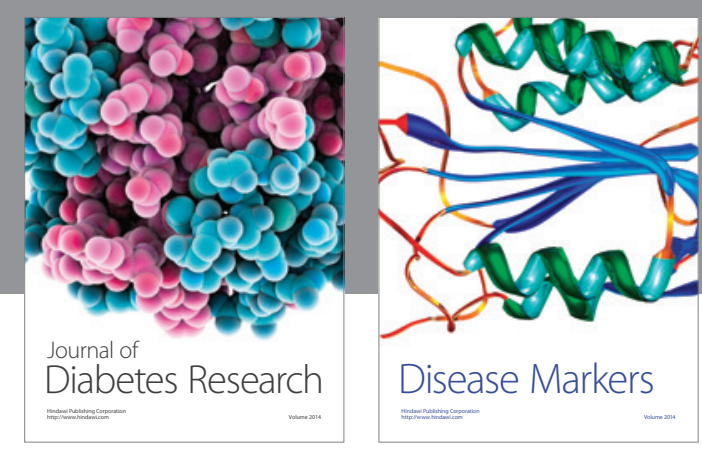

Disease Markers
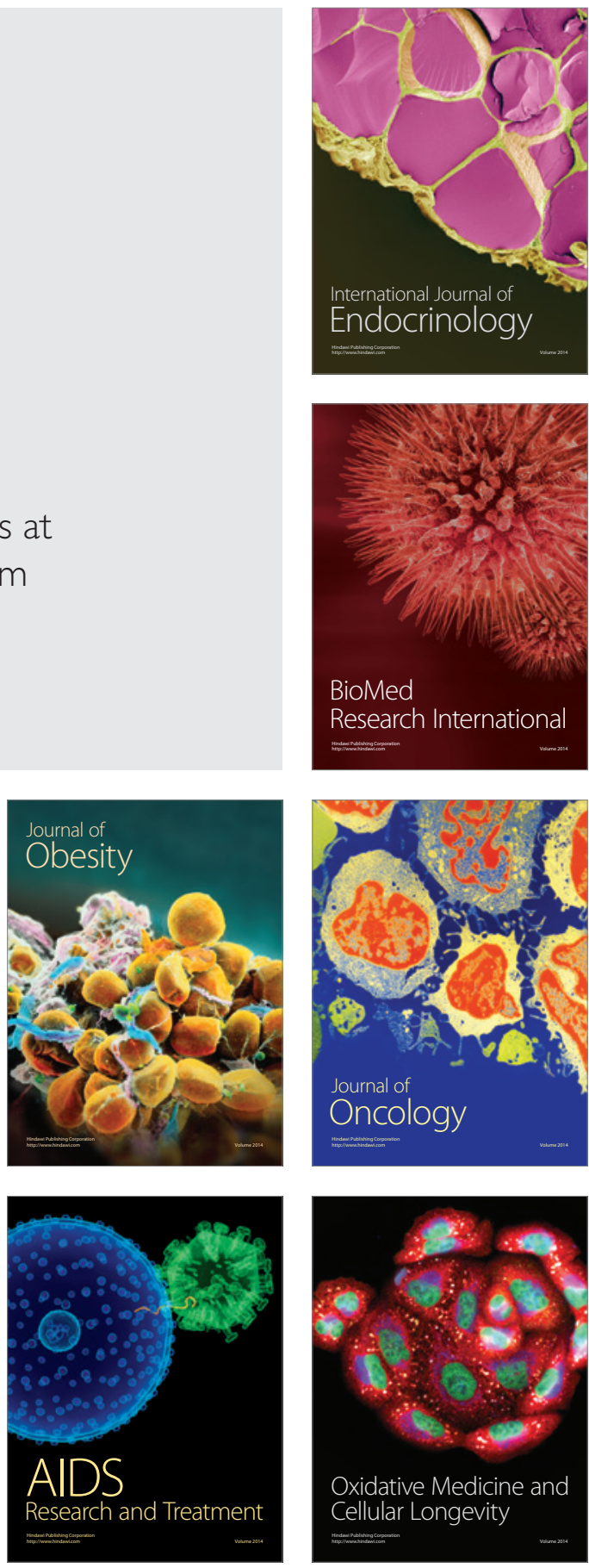